\title{
META-AVALIAÇÃO DE UMA EXTENSÃO UNIVERSITÁRIA: ESTUDO DE CASO
}

\author{
Daniela Munerato Piccolo Arroyo* \\ Maria Silvia Pinto De Moura Librandi Da Rocha**
}

Recebido em: 21 de março de 2010

Aprovado em: 08 de abril 2010

\begin{abstract}
*Mestre em Educação Área Avaliação Institucional. Especialização em Psicopedagogia e Educação; Graduação em Letras: Licenciatura Plena e Bacharelado Port./Ingl; e em Bacharelado Secretariado Bilingüe (Ingl), pela PUC-Campinas. Assistente técnica da PUC-Campinas. E-mail daniela.mpa@hotmail.com

**Doutora em Educação pela UNICAMP. Professora permanente do Programa de Pós-graduação em Educação da PUC-Campinas, membro do Grupo de Pesquisa Qualidade de Ensino.E-mail silrocha@uol.com.br
\end{abstract}

Resumo: A partir do interesse em compreender a formação do estudante universitário como futuro profissional que deve ser capaz de atuar de forma diferenciada nas diversas situações de sua trajetória profissional e pessoal e com elevado compromisso social, entendemos que os programas de extensão universitária podem cumprir importante papel neste sentido. Elegemos como campo da pesquisa, um programa de extensão de uma universidade católica, que trabalha pela inclusão social de pessoas com deficiência, numa perspectiva interdisciplinar, tendo em sua equipe professores e estudantes de diferentes áreas dos cursos de graduação. Consideramos a implantação da extensão universitária nas instituições de ensino superior e destacamos a importância dos processos de avaliação dos programas extensionistas. Desenvolvemos um trabalho de meta-avaliação, com objetivo de refletir sobre quais aspectos desta avaliação podem contribuir para a formação dos estudantes que participam de tais programas. O principal procedimento metodológico adotado foi a análise documental (relatórios anuais do Centro, instrumentos de avaliação). Além desta, realizamos entrevista com a Coordenadora do programa a fim de complementar informações e obter esclarecimentos. Entendemos que colocar em funcionamento um processo de avaliação da extensão é um trabalho complexo e que lacunas e contradições precisam ser analisadas com cuidado, porque podem limitar as contribuições que as atividades extensionistas tem em potencial para a formação dos estudantes que delas participam.

Palavras-chave: Extensão universitária. Meta-avaliação. Avaliação de extensão universitária. Inclusão.

\section{META-EVALUATION OF A UNIVERSITY EXTENSION: A CASE STUDY}

Abstract: From the interest in understanding the training of a university student as a future professional who should be able to act differently in different situations in his professional and personal path, with high social commitment, we understand that the university extension programs may play an important role in this regard. We chose as the field of research, an outreach program at a Catholic university, working for the social inclusion of people with disabilities from an interdisciplinary perspective, which has in its team teachers and students from different undergraduate programs. We consider the implementation of continuing education in institutions of higher education and highlight the importance of the evaluation of extension programs. We developed a meta-evaluation, aiming to reflect on what aspects of this evaluation may contribute to the training of students who participate in such programs. The main methodological procedure adopted was the analysis of documents (annual reports of the Center, assessment tools). Besides this, we conducted an interview with the Coordinator of the program to obtain additional information and clarification. We believe that putting in place a process to evaluate extension programs is a complex task and that gaps and contradictions must be analyzed carefully, for they may limit the contributions that the extension activities potentially have to the training of the students who take part in them.

Key words: University extension. Meta-evaluation. Evaluation of university extension programs. Inclusion. 


\section{INTRODUCAO}

Neste artigo, abordamos parte dos resultados obtidos pelo desenvolvimento de um estudo de caso, que teve como objetivo central analisar o processo de avaliação colocado em curso em um programa de extensão universitária (aqui denominado Centro), de uma universidade católica. Este Centro busca trabalhar pela inclusão social de pessoas com deficiência, numa perspectiva interdisciplinar, contando em sua equipe com colaboradores, professores e estudantes de cursos de graduação de diferentes áreas do conhecimento.

Para analisar o processo de avaliação realizado pelo Centro, ou seja, para realizar uma meta-avaliação, consideramos os procedimentos efetuados, os instrumentos utilizados e os resultados deste processo. O principal procedimento metodológico que utilizamos foi análise documental de materiais do programa de extensão, abrangendo os instrumentos de avaliação do Centro (formulários), as respostas dadas pelos extensionistas ao instrumento aplicado ao final de 2008 , as respostas dadas pelos familiares/acompanhantes ${ }^{1}$ dos usuários do programa ao instrumento aplicado em 2007, os relatórios de avaliação produzidos pelos professores integradores da Extensão, os relatórios anuais produzidos pela coordenação do programa (de 1991 a 2008) e pela Pró-Reitoria de Extensão e Assuntos Comunitários (PROEXT) da Universidade. Além das análises destes documentos, foi feita uma entrevista semi-estruturada com a coordenadora do programa, responsável por sua gestão no período de 2006-2009, com intenção de complementar as informações e esclarecer dúvidas surgidas a partir das análises dos documentos.

Estes procedimentos nos permitiram identificar os objetivos que se pretende alcançar através das estratégias de avaliação colocadas em prática nesta extensão universitária, assim como evidenciar a existência de lacunas e de contradições nas mesmas. Sem dúvida, estes resultados das análises só foram possíveis tendo em perspectiva a identidade deste programa (missão, projetos desenvolvidos, organização estrutural, composição da equipe, ações já realizadas e os resultados obtidos, procedimentos de divulgação, entre outros). Informações sobre estes aspectos foram obtidas através de acesso e análise dos folders institucionais e leitura dos relatórios anuais do Centro. Além disso, a articulação do material

1 Os acompanhantes das pessoas com deficiência são denominados cuidadores ou tutores; dentre eles, encontram-se alguns profissionais como psicólogos e psicopedagogos. Nem todas as pessoas com deficiência que freqüentam os projetos do Centro, vêm acompanhadas. Em geral, os tutores são profissionais que acompanham alguns alunos quando este acompanhamento é solicitado pela instituição da qual fazem parte e não tenham algum familiar para fazer isso. Os cuidadores são pessoas contratadas pelas famílias para cuidar da pessoa com deficiência em todos os aspectos (locomoção, higiene, alimentação). 
analisado com outros trabalhos científicos e aportes que encontramos a partir da revisão da literatura mostrou-se imprescindível.

No desenvolvimento da pesquisa, procuramos responder a perguntas quanto aos pontos fortes e às fragilidades do processo de avaliação realizado pelo Centro. Estivemos especialmente interessadas em saber em que aspectos esta avaliação contribui para a formação dos estudantes que participam deste programa de extensão, a partir da adoção do conceito de avaliação formativa.

Entendemos que somente através do uso de procedimentos de avaliação rigorosos, e sistemáticos é possível fazer avançar a extensão universitária e aprimorá-la. Mas, faze-la avançar em que direção? Quais devem ser os compromissos que os programas de extensão devem assumir? Quais são os papéis que devem desempenhar na vida universitária? De nossa perspectiva algumas respostas a estas questões precisam ser abordadas antes da apresentação dos resultados da pesquisa e de suas análises. É o que faremos, a seguir.

\section{O PAPEL DA EXTENSÃO UNIVERSITÁRIA}

O termo "extensão" surgiu na legislação educacional brasileira em 1931, no primeiro Estatuto das Universidades Brasileiras, referindo-se ao oferecimento de cursos e conferências de caráter educacional, como "organismo da vida social da Universidade" (SOUSA, 2000, p. 16), e só ressurge no texto da Lei ${ }^{\circ}$ 5.540/68, tornando-a obrigatória em todas as Instituições de Ensino Superior (IES) do Brasil.

Para ser compreendido com mais profundidade, o papel da extensão universitária deve ser analisado à luz do papel da universidade. Quanto a isso, consideramos importante destacar dois compromissos que se diferenciam, mas também se articulam.

Por um lado, a missão e razão de existência das universidades está em produzir e difundir o conhecimento, com objetivos mais ambiciosos do que os propostos para os níveis fundamental e médio. Conforme Silva (2000, p. 43), esta difusão de conhecimento se organiza em duas etapas: "intramuros", operacionalizada através das atividades realizadas internamente nos ambientes universitários, portanto, principalmente através das ações de ensino; e "extramuros", direcionadas aos grupos que não pertencem aos corpos docente e discente da instituição universitária; portanto, através das ações de extensão.

Por outro lado, "a missão pública da educação superior é formar cidadãos profissional e cientificamente competentes, bem como comprometidos com o desenvolvimento social do país" (CALDERON, 2007, p. 58). E, dentre os 
caminhos que a universidade tem para desenvolver e oferecer uma formação mais completa aos seus estudantes, através da proposição de interlocução entre os saberes e a formação crítica de novos profissionais - os programas de extensão universitária mostram-se bastante promissores, quando se desenvolvem como atos políticos, isto é, como ações que podem transformar determinada situação social.

A implementação e desenvolvimento de ações extensionistas requerem que as universidades assumam uma concepção que valorize a atuação das IES junto à comunidade local e, conseqüentemente, à sociedade como um todo. Com isto, buscar o estreitamento e o compartilhamento de conhecimentos e saberes que efetivem e consolidem o papel do ensino neste nível, contribuindo para a transformação social a que deve se propor a universidade. A extensão universitária deve ser concebida, portanto, como ação que visa, principalmente, a formação do indivíduo-cidadão que irá atuar nos diversos segmentos profissionais, e que, provavelmente, neles encontrará situações nem sempre previstas nos conteúdos de teor específico dos cursos de graduação e que ultrapassam a necessidade de conhecimentos técnico-científicos, exigindo dele posições socialmente comprometidas.

Segundo o Programa de Extensão da Secretaria de Ensino Superior-MEC/ Brasil (PROEXT), extensão “é o processo educativo, cultural e científico que articula o ensino e a pesquisa de forma indissociável e viabiliza a relação transformadora entre a universidade e a sociedade" (BRASIL, 2003). Esta definição marca que os programas de extensão devem buscar desconstruir o restrito aspecto assistencialista e devem estar associados a iniciativas que promovam debates acerca das questões mais melindrosas, mais difíceis da organização de nossa sociedade. As ações extensionistas não devem perder de vista as carências materiais e de conhecimentos de grande parte da população brasileira, que ocasionam a não-autonomia destas pessoas, impossibilita-as de atingirem sua emancipação econômica e social, em virtude do aprisionamento a um sistema político muitas vezes corrupto, particularizado, que frequentemente não favorece o desenvolvimento humano em seu sentido mais pleno.

Em todos os trabalhos de extensão consultados ${ }^{2}$, independentemente de suas especificidades e dos segmentos da população atendida, consta a assunção de

2 Fizemos uma compilação dos fóruns onde têm sido debatidos com mais riqueza os temas relacionados à extensão universitária, como os Congressos Brasileiros de Extensão Universitária (CBEUs), a Rede Nacional de Extensão (RENEX), os Fóruns de Extensão (FOREXT) e os Seminários de Metodologia para Projetos de Extensão (SEMPE). Estes têm sido importante campo de debate, divulgação e estímulo à propagação das ações extensionistas, principalmente quanto a questões sobre avaliação e possíveis caminhos para seu desenvolvimento. (ARROYO, 2010) 
compromisso em colaborar com a integração social dos indivíduos a quem as ações extensionistas se dirige. Entretanto, isto não significa a ausência de diferenças e/ou contradições no seu delineamento e na sua concretização.

Um dos pontos mais delicados neste debate diz respeito a perigos sempre presentes de que a extensão universitária sirva como instrumento útil no processo de desresponsabilização do Estado de suas obrigações sociais com a população. A questão da transferência de responsabilidades refere-se ao deslocamento daquilo que deveria ser realizado pelo Estado e que - pelas transformações ocorridas nas políticas estatais e seus efeitos do ensino superior - acaba sendo realizado, ao menos em parte, pelas universidades. Este posicionamento do Estado surge a partir do neoliberalismo, mantendo-se já há vários anos e atinge todos os setores que dizem respeito à vida dos cidadãos (como educação, saúde, saneamento, por exemplo). Para atender às exigências do capital, começaram a ser incentivadas parcerias entre o poder público e o privado, assumindo o Estado meramente o papel de regulador das ações efetivadas para atender às necessidades da população brasileira.

O risco de que os programas de extensão universitária assumam parte destas responsabilidades do Estado estão presentes desde as primeiras iniciativas extensionistas. Nogueira (2005, p. 7) explica que as políticas da extensão universitária tiveram início no Brasil a partir do tenso período da ditadura militar, tendendo a fazer da extensão universitária uma estratégia que visava "minimizar, com o assistencialismo, os efeitos negativos das políticas macroeconômicas sobre o emprego, os salários, as condições de vida do povo, os investimentos em infra-estrutura, etc". Em síntese, podemos dizer que desde as primeiras iniciativas de realização de projetos de extensão, tais como o Projeto Rondon e os Centros Rurais de Treinamento e Ação Comunitária (CRUTAC) ${ }^{3}$ é possível identificar diferentes posições sobre quais papéis e compromissos devem ter as atividades extensionistas que as universidades devem realizar, dependentes das diferentes posições políticas implicadas: o Projeto Rondon, cujo objetivo principal é aproximar os estudantes da realidade carente do Brasil; e os CRUTAC, que inicialmente levava os estudantes ao interior do Estado do Piauí para treinamento em sua área de formação profissional. Assim, definir precisamente o que é/deve ser um projeto de extensão universitária não é tarefa simples nem consensual.

3 Projetos que surgiram em 1966 pelo entendimento de que a universidade deve ser responsável por estabelecer uma ponte permanente com todos os setores da sociedade, a fim de promover a cidadania e a participação do estudante universitário na sociedade. 
Podemos dizer que as discussões e os alertas quanto aos perigos de que os projetos de extensão tenham caráter e filiação ao assistencialismo são constantes na história da extensão universitária. Por exemplo, diz Silva (2000, p. 51) que:

a universidade, [...], não pode ser conivente com práticas assistencialistas, em que préstimos dos que detêm o saber são solicitados de tal modo que ocorre a perpetuação de relações de poder entre os que servem e os que são servidos. A socialização do conhecimento deve ser entendida, portanto, como atitude que possibilita a emancipação dos sujeitos envolvidos no processo.

Nesta mesma direção, Thiollent (2002, p. 2) argumenta que extensão é diferente de assistência social, de responsabilidade social e de prestação de serviços, sendo, a extensão universitária uma das ferramentas de transbordamento de conhecimento que uma instituição pode realizar:

A extensão também é uma construção ou (re)construção de conhecimento, envolvendo, além dos universitários, atores e públicos com culturas, interesses, níveis de educação diferenciados. A construção extensionista não está limitada aos pares, abrange uma grande diversidade de públicos externos com os quais é preciso estabelecer uma interlocução para identificar problemas, informar, capacitar e propor soluções.

Podemos, então, dizer que as relações da universidade com a sociedade, através da extensão universitária, devem ser realizadas com a principal tarefa de preocupar-se com a formação do cidadão, em duplo sentido: dos novos profissionais que irão atuar nos diversos setores sociais e dos membros da comunidade, o público externo a quem estas ações extensionistas se dirigem, buscando contribuir, concretamente, para a construção de melhores condições de cidadania.

Um último aspecto deve ser mencionado em relação às características da extensão universitária refere-se à indissociabilidade ensino-pesquisa-extensão. Apoiando-nos nos autores estudados no presente trabalho, entendemos que a universidade não deve dedicar-se exclusivamente ao ensino, o qual não pode restringir-se à mera transmissão de conhecimentos. Nem a pesquisa pode ser um segmento à parte, descontextualizado; embora seja, claro, uma importante função das IES, deve ter uma significação social, relacionar-se o máximo possível com os interesses da comunidade. Numa universidade, ambos os eixos devem estar respaldados na relevância da sua significação social, o que pode/ deve ser intensificado por suas articulações com o âmbito da extensão. 
Severino $(2007$, p. 31) ressalta que

A extensão se torna exigência intrínseca do ensino superior em decorrência dos compromissos do conhecimento e da educação com a sociedade, uma vez que tais processos só se legitimam, inclusive adquirindo sua chancela ética, se expressarem envolvimento com os interesses objetivos da população como um todo. O que se desenrola no interior da universidade, tanto do ponto de vista da construção do conhecimento, sob o ângulo da pesquisa, como de sua transmissão, sob o ângulo do ensino, tem a ver diretamente com os interesses da sociedade.

Trabalhar pela indissociabilidade entre o ensino, a pesquisa e a extensão significa preocupar-se em constituir uma formação não segregada, como eram as cátedras do início do ensino superior. Sem dúvida, esta articulação também não é algo simples. Reconhecemos que estes aspectos não estão, ainda, tão claros para todos, o que mostra a importância de se debater as diferentes concepções, as diversas formas de implantação e de avaliação da extensão universitária nos eventos científicos, nos fóruns e internamente, em processos desenvolvidos pelos próprios programas e pelos gestores da universidade.

\section{AVALIAÇÃO DE PROGRAMAS DE EXTENSÃO}

Avaliar é uma ação que deve estar sempre em processo de transformação - nunca estará suficiente, terminada - e que deve se colocar à busca pela continuidade e melhoria daquilo que se avalia, bem como dos próprios processos, procedimentos e instrumentos nela utilizados. Uma avaliação sempre tem caráter transformador, porque afeta a vida das pessoas envolvidas, produz efeitos sobre elas, devendo ser importante instrumento para mover a tomada de decisões diante dos resultados obtidos.

Para Worthen, Sanders e Fitzpatrick (2004, p. 35), a "avaliação é identificação, esclarecimento e aplicação de critérios defensáveis para determinar o valor, a qualidade, a utilidade, a eficácia ou a importância do objeto avaliado em relação a estes critérios". Assim, qualquer avaliação requer escolhas e tomadas de posição, eleição de determinados aspectos e/ou dimensões a serem focalizados, bem como a colocação em planos secundários de outros aspectos e/ou dimensões. Estas escolhas são orientadas por valores e, em geral, nos processos de avaliação predominam os dos avaliadores. Destacamos que a avaliação é um fenômeno essencialmente complexo, que pode ser encaminhado por múltiplos procedimentos e que envolve relações de poder, tensões, julgamentos e escalas 
de valores; além disso, normalmente as avaliações não podem produzir certezas ou respostas finais.

Quando se analisa de que modos as pessoas envolvidas num processo avaliativo participam dele. Neste caso, uma avaliação pode ser autoritária, participativa ou democrática. A modalidade de avaliação autoritária refere-se à implantação de um processo em que tudo (ou quase tudo) está nas mãos do avaliador: é ele quem decide o que, como e quando avaliar. Decide também sobre os rumos a serem dados aos resultados da avaliação. Ao(s) avaliado(s) resta submeterem-se ao processo e às conseqüências da avaliação, sejam elas punitivas ou recompensadoras. As qualificações de uma avaliação como participativa ou democrática têm sido, muitas vezes, tomadas como sinônimos, por oposição à avaliação autoritária. De fato, em uma e em outra, as posições ocupadas pelos envolvidos é bastante diferente da simples submissão, já que nelas, aqueles que são avaliados têm direito à voz, podendo colaborar em tomadas de decisão necessárias nas diversas etapas de um processo avaliativo.

Toda avaliação pode, também, ser categorizada segundo suas funções, dentre as quais importa-nos destacar as de controle, regulação, formação e emancipação. Uma avaliação sempre busca cumprir distintas finalidades, não sendo possível reduzi-la apenas à mera aplicação de um instrumento ou a um mecanismo técnico. Em geral, uma avaliação desenvolvida com as finalidades de primeiro tipo, busca produzir ajustamento e conservação das pessoas e/ou dos processos avaliados, sendo realizada mais com objetivo de fiscalização. A função de regulação, muitas vezes tem características burocráticas e legalistas. Em geral, uma avaliação que busca promover formação ou emancipação, tem como compromisso provocar ou permitir transformações das pessoas e/ou dos processos avaliados.

Dias Sobrinho (2002, p. 10), traz contribuições para argumentarmos sobre a importância das avaliações formativas e a adequação deste conceito em razão das posições por nós assumidas em relação ao que deve orientar um programa de extensão. Diz o autor:

Mais que resultados obtidos pelos alunos ou por uma instituição, o objeto em foco [deve] ser prioritariamente as relações sócio-educativas, isto é, as relações intersubjetivas concretas, as representações, as estruturas, em função da formação do estudante. A formação como fim, portanto, formação em seu sentido mais completo.

Entendemos ser importante destacar, a partir deste trecho, que a palavra formação pode ser usada para qualificar um processo de avaliação segundo 
múltiplos significados e sentidos, embora ela sempre implique em transformação. Mas as transformações pretendidas como resultado de um processo de avaliação formativa podem ser orientadas para várias direções, como, de um certo modo, nos alerta Dias Sobrinho ( p. 52) no que diz acima e quando torna mais preciso o sentido que a palavra tem em sua obra:

Se a educação prioriza os valores da formação humana integral, a avaliação que lhe corresponde também estará vinculada a essa concepção. [...] estará dirigida principalmente aos valores humanos fundamentais e duradouros, no sentido de que são universais na história da humanidade, como os de justiça social, paz, pertinência, cidadania, independência intelectual, felicidade, solidariedade, liberdade, fraternidade, igualdade, respeito à alteridade e outros.

A avaliação formativa, segundo o nosso entendimento, é aquela que possibilita a ação contínua de verificação e acompanhamento de um processo enquanto ele ocorre, podendo permitir identificar com mais segurança o desenvolvimento das ações propostas, bem como dar o seu encaminhamento para melhorá-las ou adequá-las aos objetivos do ensino proposto, bem como à missão da instituição. Para que isto ocorra, é imprescindível que a IES estabeleça objetivos claros e possíveis de serem atingidos, considerando ainda, o contexto social de seus participantes. Segundo Villas Boas (2006), na avaliação formativa, considerase também o envolvimento da comunidade acadêmica nas decisões sobre a definição dos critérios de avaliação, de modo que lhe possibilite compreender o processo pelo qual está passando e o que é esperado como resultado.

Em síntese, concordamos com a afirmação de que 'não há um modelo único de avaliação, uma só concepção, uma só prática. Falar de avaliação é necessariamente tratar de avaliações. Plurais, mas não aleatórias, descomprometidas, devem ser confiáveis e justas, técnica e eticamente'. (DIAS SOBRINHO, 2002, p. 40)

Quanto à avaliação da extensão, é importante reconhecer que ela é bastante recente. Os investimentos para a avaliação da extensão universitária, compondo uma Política Nacional de Extensão, começaram a ser fundamentados apenas a partir do Sistema Nacional de Avaliação do Ensino Superior (SINAES), colocado em funcionamento em 2004 (BRASIL, 2004), no governo Lula, em substituição ao Exame Nacional de Cursos (ENC); a tarefa do SINAES é analisar as instituições, os cursos e os estudantes, em busca de

(i) identificar mérito e valor das instituições, áreas, cursos e programas, nas dimensões de ensino, pesquisa, extensão, gestão e formação; 
(ii) melhorar a qualidade da educação superior, orientar a expansão da sua oferta; (iii) promover a responsabilidade social das IES, respeitando a identidade institucional e a sua autonomia.

Prevê-se neste sistema de avaliação a atenção a aspectos relativos aos eixos de ensino, pesquisa e extensão, destacando-se neles as dimensões de responsabilidade social, a gestão da instituição, o corpo docente e as instalações. As informações obtidas são utilizadas para orientação às IES, com objetivos, ao menos declarados, de auxiliá-las na superação dos possíveis pontos frágeis encontrados e para embasar políticas públicas.

Assume-se, neste sistema, uma preocupação em resgatar o papel da universidade para a sociedade, considerando suas necessidades e carências. Diante da falta de políticas públicas específicas para a extensão universitária, o SINAES, segundo Elpo (2004, p. 2), "surge para adequar o processo de avaliação de forma globalizante, articulando auto-avaliação, interna e externa, buscando atender às questões pertinentes a avaliação de toda a instituição, incluindo um tópico específico sobre a avaliação da extensão universitária", representando um avanço nesta questão. Com este sistema, amplia-se a proposta de avaliação das IES, e a inclusão da avaliação dos programas de extensão como objeto de análises deve permitir, ao menos por princípio, uma reflexão mais aprofundada sobre as ações desenvolvidas. Em tese, isto faz com que as ações extensionistas sejam valorizadas, ganhem visibilidade e rigor e seus resultados sejam reconhecidos, no que tange às ações de intervenção social.

$\mathrm{Na}$ prática, entretanto, tudo indica que há importantes desafios a serem conhecidos e superados para a implantação e implementação de processos de avaliação da extensão. As informações lacunares que encontramos em vários trabalhos ${ }^{4}$ que abordam a temática nos sugerem que a avaliação da extensão pode estar sendo concebida/realizada, ao menos em algumas situações, mais como instrumento que justifica ações ou para gerar relatórios de prestação de contas - ou seja, numa concepção pragmática - do que como processo reflexivo, crítico, formativo e/ou emancipador. Ressaltamos que o termo formativo é várias vezes utilizado, mas, não raro, apenas para mencionar-se que a avaliação dos programas deve promover reflexão e revisão das atividades, direcionando os próximos passos para melhoria e correção dos problemas e dificuldades ou mesmo para afirmar o que tem tido êxito. De nosso ponto de vista, portanto, o termo perde o vigor de sua articulação com a questão do desenvolvimento de

4 Baseamo-nos, para fazer esta afirmação, nas publicações dos anais dos Congressos Brasileiros de Extensão Universitária, atendo-nos, de modo particular, aos que se integram ao eixo temático "avaliação". 
valores tais como os de justiça social, paz, pertinência, cidadania, independência intelectual, felicidade, solidariedade, liberdade, fraternidade, igualdade, respeito à alteridade e outros. (DIAS SOBRINHO, 2002, p. 52)

Compartilhamos com Bartnik (2009, p. 105) suas afirmativas sobre o quanto é difícil realizar avaliação da extensão nas instituições e o quanto isto ainda não tem sido feito de modo sistemático e aprofundado. Para esta autora, há poucos critérios e modelos que forneçam as diretrizes necessárias à realização desta avaliação, bem como pouca clareza dos modos como deve ser feita; em grande medida, a escassez destes elementos é decorrente da ausência de uma política de extensão que oriente as instituições em seus processos de avaliação das ações extensionistas.

Para construir uma avaliação da extensão torna-se necessário um caminho que pondere as complexidades das práticas e ações da extensão, considerando as relações que a universidade faz com quem nela se encontra, com quem nela trabalha, com quem dela sai e quem dela depende.

Ou seja, não é possível conceber uma avaliação de extensão nos mesmos moldes dos objetivos e procedimentos utilizados para avaliar as demais ações da universidade, como por exemplo, os de ensino-aprendizagem e os resultados obtidos em pesquisas. É necessário construir instrumentos a partir dos quais se possa também identificar fragilidades, fortalecer os vínculos com o ensino e a pesquisa, direcionar a elaboração das políticas institucionais, projetar as ações da universidade dentro e fora dela, segundo o contexto social no qual ela se encontra, bem como "ter seus resultados como mecanismo de emancipação, aperfeiçoamento e planejamento de gestão”. (BARTNIK, 2009, p. 105)

Finalizando esta parte introdutória, é importante lembrar com Dias Sobrinho (2002) que para a avaliação de quaisquer programas de extensão é necessário realizar uma análise segundo os objetivos que os próprios programas desta natureza se dispõem a atingir, tanto os gerais, parte integrante e necessária de todo programa, quanto os específicos, decorrentes das opções singulares de cada um deles ${ }^{5}$. Por esta razão, traremos, a seguir, informações sobre o Centro, objeto deste estudo.

5 É importante reconhecer que este autor afirma também a necessidade de se considerar os aspectos políticos educacionais e as reformas no ensino superior, ou seja, de incluir no processo avaliativo questões que advém de um universo mais amplo. Entretanto, dados os limites deste artigo, destacamos seus apontamentos sobre as questões atinentes aos objetivos da extensão universitária (de forma geral e dos programas específicos, em particular). 


\section{O PROGRAMA DE EXTENSÃO UNIVERSITÁRIA ESTUDADO}

O Centro nasceu a partir de um projeto desenvolvido pela ação voluntária de alguns docentes da Universidade, em parceria com a Associação de Pais de Alunos Excepcionais (APAE), em 1987, oferecendo atividades para pessoas com deficiência, vindas da comunidade externa, inicialmente crianças com deficiência visual. Em 1990, o projeto foi aprovado pela Universidade, por reconhecer que os profissionais envolvidos nos trabalhos já teriam condições para realizar uma atuação mais ampliada, com proposta de

promover a reinserção social da pessoa portadora de deficiência ${ }^{6}$, facilitando seu acesso a todas as classes sociais, indistintamente, através da estimulação de suas aptidões artístico-esportivas. (PROJETO ORIGINAL, 1990)

A partir de 1995, o programa demonstra maior preocupação com a formação dos estudantes da Universidade que nele atuavam, materializada através da intensificação de realização de pesquisas, supervisão de monografias e de estágios, o que, para nós, indica incremento da busca de capacitação da equipe e dos extensionistas, bem como o aumento de preocupação com a qualidade das articulações entre ensino, pesquisa e extensão, procurando atuar em consonância com as demais ações e projetos da Universidade.

Pelas características do programa, sinaliza-se a possibilidade para os graduandos de experiências que podem contribuir para sua formação integral, por várias razões, dentre as quais, a oportunidade de perceberem-se como parte integrante e necessária nos esforços acadêmicos para transformar a condição das pessoas com deficiência e a oportunidade de aprenderem que esta transformação requer a congregação de conhecimentos de diversas áreas, exigindo, assim, a construção de competências para trabalhar em equipe interdisciplinar. Segundo o material divulgado pelo Centro, "a equipe de profissionais que dele faz parte realiza um trabalho articulado de fundamentação teórico-prática, que resulta em ações e projetos que se propõe serem coerentes com a missão da Instituição", visando "contribuir para viabilização de processos educacionais de excelência, possibilitando uma formação flexível, polivalente e interdisciplinar". A convivência entre os extensionistas e as pessoas com deficiência que participam do programa é apontada como condição extremamente favorecedora da formação integral da pessoa humana.

6 Note-se que, à época, ainda se utilizava a nomenclatura 'pessoa portadora de deficiência', a qual, contemporaneamente, foi substituída por 'pessoa com deficiência'. 
Em 2009, o Centro atendeu a 534 pessoas com as diversas deficiências: visual, auditiva, física, cognitiva. Estas pessoas pertencem à comunidade externa, vindos de diversos pontos da cidade e de sua redondeza por iniciativa própria, ou trazidas pelas instituições especializadas que freqüentam. Além das instituições, há famílias que procuram o Centro por indicação de amigos ou de profissionais da área da saúde que os atendem, ou ainda por terem sido alcançados de alguma forma pela divulgação que o Centro realiza (geralmente, através dos eventos e palestras, e distribuição de folheto nas instituições atendidas).

Os projetos são oferecidos a pessoas com deficiência, de todas as idades, numa faixa etária entre 15 e 65 anos. Há ainda atividades oferecidas aos seus familiares/acompanhantes (mães, pais, cuidadores, tutores, profissionais), tais como pintura, música e inclusão digital.

\section{OBJETIVO DO CENTRO}

O objetivo principal do Centro, registrado em seus relatórios anuais por nós analisados, sempre foi a atuação pela inclusão social de pessoas com deficiência através de trabalho interdisciplinar. Dentre os objetivos específicos, descritos no Relatório Anual de 2008, consideramos dois deles como de maior destaque: (i) "gerar conhecimentos teóricos e práticos", e (ii) "realizar iniciativas que promovam a troca de conhecimentos científicos, profissionais e culturais", o que parece marcar a atuação de um programa que atende pessoas com deficiência para um Centro que assume compromissos com os outros eixos da Universidade. Em razão do permanente objetivo principal desta extensão universitária, é necessário fazer algumas considerações sobre o tema da inclusão de pessoas com deficiência.

Historicamente, estas pessoas têm ocupado uma posição marginal na nossa sociedade e têm sido privadas do acesso e usufruto de grande parte dos bens e de práticas culturais, tais como de uma escolarização de qualidade, do mundo do trabalho e do lazer. Quando não são excluídas quase totalmente, dificilmente escapam de serem objeto de estereótipos, preconceitos, estigmas e de uma diminuição grave das expectativas que os outros tem em relação às suas potencialidades. Muitas vezes, no melhor dos casos, as pessoas com deficiência são objeto de pena e de caridade, o que sem dúvida contribui muito pouco para que possam se desenvolver e ultrapassar a escassez de oportunidades que encontram na vida. Incluir é mais do que integrar a pessoa. É fazê-la parte do processo, é permitir-lhe estar dentro, estar com, em seu todo. 
Neste sentido, no decorrer da história, várias ações vem sendo implementadas com o objetivo de dar melhores condições de vida para as pessoas com deficiência, dentre elas, as alterações dos termos a elas designadas como nomenclatura, as propostas de melhorias para seu acesso à educação, à saúde, aos serviços públicos, ao mercado de trabalho, à cultura, ao lazer, entre tantos outros. Tais ações vêm sendo debatidas e exigidas por meio de entidades que cumprem importante papel na produção e divulgação de documentos internacionais, que visam a construção de uma sociedade inclusiva, como as declarações de Cuenca (Equador) e a de Salamanca (Espanha) bem como, na esfera brasileira, a produção de legislação que diz respeito aos direitos dos cidadãos. Trata-se de uma luta que tem por objetivo considerar todo indivíduo, independentemente de sua condição física ou intelectual, seja apenas pessoa.

\section{A PARTICIPAÇÃO DOS ALUNOS-EXTENSIONISTAS}

O ingresso dos estudantes no Centro é realizado por meio de um processo seletivo efetivado logo após o início do ano letivo, divulgando-se no site da Universidade a abertura das inscrições. Os inscritos são convocados para um encontro, que visa promover a integração entre os candidatos e a equipe do Centro, com dinâmicas de grupo para sensibilização quanto à diversidade entre as pessoas e quanto ao tema da inclusão.

Os extensionistas são distribuídos nos projetos do Centro, nos quais são programadas as atividades de esporte, lazer, profissionalização, artes, informática e de saúde, inicialmente conforme o interesse despertado no encontro geral, e participam por um período inicial de trinta dias, para que possam conhecer melhor a proposta. Neste período de experiência, são também são avaliados pelo coordenador de cada projeto, no que se refere a interesse, participação, assiduidade, atendimento a normas e regras, disponibilidade, respeito com os colegas de equipe e com as pessoas com deficiência. Os extensionistas que se integram ao Centro podem ser bolsistas, recebendo bolsa-estímulo conforme a carga-horária que exercem; ou voluntários (no caso de estudantes que tenham outros recursos para garantir seus estudos, como bolsa PROUNI, e de iniciação científica).

Com o intuito de evidenciar a dimensão das ações operacionalizadas pelo Centro e o montante de graduandos envolvidos para que pudessem ser realizadas, informamos que no ano de 2008, o Centro pode contar com a participação de 178 extensionistas, chegando ao seu final com 110 estudantes, dos quais 63 eram bolsistas e 47 eram voluntários. Na equipe de profissionais, naquele 
ano, o Centro contou com nove professores e quatro funcionários; e o número total de pessoas com deficiência atendidas foi 528 (distribuídas entre 142 provenientes das instituições que dele participavam e 386 que procuraram o Centro individualmente).

\section{O PROCESSO DE AVALIAÇÃO DO CENTRO E SUA INTEGRAÇÃO À AVALIAÇÃO INSTITUCIONAL}

Para se compreender qualquer processo de avaliação, de modo mais aprofundado, é importante buscar responder a algumas questões: quem avalia? Quem está sendo avaliado? Quais são os procedimentos utilizados para avaliar? Quais são as finalidades da avaliação? Quem se beneficia dela? Quem pode ser prejudicado por ela? Que usos são feitos dos seus resultados?

O processo de avaliação sistemática da Universidade começou a ser construído em 2005, a partir da implantação do Programa de Auto-Avaliação Institucional (PROAVI). Em 2007, o Centro iniciou a implantação de um processo de avaliação também mais sistematizado, procurando envolver a equipe de profissionais e estudantes. Antes disto eram feitas avaliações somente pelo docente, relatando os resultados e dificuldades no relatório final, compondo o relatório geral do Centro, encaminhado à PROEXT, cujas informações compunham o relatório geral da Universidade, como ainda ocorre atualmente.

Os processos avaliativos desencadeados pelo PROAVI procuram reafirmar a identidade católica e comunitária desta IES, com vistas ao aprimoramento da qualidade de seus cursos e demais atividades educativas, culturais e artísticas. Alguns projetos de avaliação que integram o PROAVI dão continuidade a processos avaliativos que já haviam sido desencadeados antes da criação deste órgão; outros são novos, incluindo o que se refere ao Centro em estudo.

Quanto à avaliação realizada especificamente no Centro, o processo tem envolvido, regularmente, os docentes e os estudantes; em 2007, incluiu também os familiares/acompanhantes das pessoas que o freqüentam, Por fim, até onde foi possível obtermos informações, não há registros de existência de instrumentos e/ou procedimentos para que as próprias pessoas com deficiência avaliem o programa; portanto, tudo indica que ao longo da trajetória de existência do Centro este grupo de pessoas não está incluído nos processos avaliativos.

A seguir, como objeto de nossas análises, detalharemos, especialmente a participação dos estudantes-extensionistas, embora também façamos algumas considerações sobre as participações dos docentes-integradores, dos familiares e/ou responsáveis e sobre a ausência de participação das pessoas com deficiência. 
Ao final de cada ano, os extensionistas são chamados para participar da avaliação geral, pela Coordenadora, que divulga este convite a cada um dos grupos destacando a importância do envolvimento dos extensionistas nesta tarefa. Os docentes responsáveis reúnem-se com os extensionistas e revisam o planejamento do início do ano, levantando dificuldades e avanços. Além disso, os extensionistas respondem, individualmente, a um formulário de avaliação, elaborado com questões fechadas e abertas, sem identificarem-se. As respostas são lidas pelo integrador para propor adequações para o ano seguinte. Os extensionistas são orientados a preparar um relatório individual das atividades desenvolvidas em cada um dos projetos dos quais participou, com a finalidade de descrever, sob o seu olhar, o que significou a sua participação, considerando objetivos propostos.

Ao final do processo, antes de os integradores encaminharem o material e seus respectivos relatórios para leitura, análises e posterior inserção no relatório anual do Centro, a Coordenadora convoca uma reunião com os mesmos, a fim de debater as principais ações realizadas no ano, ocasião em que podem comentar os avanços, cumprimento de metas e as dificuldades encontradas no desenvolvimento das atividades, antes de redigir o relatório.

\section{META-AVALIAÇÃO: REFLEXÕES ANALÍTICAS SOBRE A AVALIAÇÃO NO CENTRO}

A partir do mapeamento dos procedimentos e dos instrumentos utilizados, da leitura destes últimos e dos resultados de sua aplicação, realizamos reflexões analíticas à luz das diretrizes indicadas pelos autores estudados (especialistas nos temas extensão, inclusão social de pessoas com deficiência e avaliação. Como ponto de partida, usamos como referência para a construção de nossas categorias a obra de Worthen, Sanders e Fitzpatrick (2004).

Da extensa obra de Worthen, Sanders e Fitzpatrick (2004, p. 597-599), destacamos suas proposições sobre meta-avaliação, ou seja, sobre como avaliar avaliações. Neste campo, a partir da publicação do Joint Comitee ${ }^{7}$, os autores apresentam as seguintes diretrizes para análises sobre a qualidade de processos de avaliação:

- Utilidade: garantir que a avaliação atenda às necessidades de informação dos usuários potenciais.

7 Joint Comittee on Standards for Education Evaluation (Comitê Misto sobre Diretrizes para a Avaliação Educacional), criado em 1975, sendo uma coalizão da maioria dos profissionais ligados à qualidade da avaliação educacional nos Estados Unidos da América. http://www.jcsee.org. Acesso em agosto de 2009. 
- Viabilidade: assegurar que uma avaliação seja realista, prudente, diplomática e moderada.

- Propriedade: assegurar que uma avaliação seja conduzida de forma juridicamente legítima, ética e com a devida consideração pelo bemestar dos envolvidos no estudo, bem como dos afetados pelos resultados.

- Precisão: garantir que uma avaliação revele e transmita informações tecnicamente adequadas sobre as características que determinam o valor ou mérito do programa que está sendo avaliado.

Worthen, Sanders e Fitzpatrick (2004, p. 600) argumentam que a importância destas diretrizes encontra-se em servirem "para planejar e revisar avaliações, para organizar a formação na área da avaliação e para monitorar ou fazer auditorias de avaliações formalmente encomendadas". Na obra sugere-se alguns passos para realização de uma avaliação, cabendo ao avaliador discernir quanto às opções e vantagens de cada diretriz, subdivididas em várias categorias. Dentre elas, elegemos as que consideramos como mais produtivas para nossas análises: alcance e seleção das informações coletadas, significando que "as informações coletadas devem ser selecionadas de maneira abrangente para responder a perguntas pertinentes sobre o programa e ser receptivas às necessidades e aos interesses dos clientes e de outros envolvidos"; completude e justiça, na qual indica-se que a avaliação deve "examinar e documentar os pontos fortes e fracos do programa que está sendo avaliado, para que os pontos fortes sejam enfatizados e as áreas problemáticas sejam melhoradas".

No caso estudado, o trabalho analítico requeria localizar de que modo os procedimentos e instrumentos utilizados no Centro para sua avaliação são sensíveis aos fundamentos de uma extensão de qualidade que destacamos (quais sejam, a formação ampla dos extensionistas e a articulação entre ensino, pesquisa e extensão) e desta extensão específica (ressaltando questões relativas à inclusão social das pessoas com deficiência). Sendo assim, as categorias propostas foram ajustadas nos pontos que nos pareceram necessários para realizar esta meta-avaliação de modo mais aprofundado.

Com o estudo realizado entendemos que "as necessidades e os interesses dos clientes e de outros envolvidos", dizem respeito à que o trabalho desenvolvido no Centro constitua-se como um ponto importante de articulação da

8 Na dissertação de mestrado da qual este artigo se originou (ARROYO, 2010), as categorias "praticidade dos procedimentos", "descrição de finalidades dos procedimentos" e "confiabilidade das fontes de informação" também foram consideradas para o trabalho analítico de meta-avaliação. 
ação extensionista com as ações de ensino e pesquisa, tendo como objetivo comum a interdisciplinaridade, a inclusão social das pessoas com deficiência (relativa ao compromisso com a construção de um trabalho que, se não tem condições de mudar radicalmente o que a sociedade permite a essas pessoas, ao menos tem condições de ajudá-las a se instrumentalizar para lutar por seus direitos).

Logo, as "perguntas pertinentes" sobre o programa e a identificação de "pontos fortes" e de "áreas problemáticas" dos instrumentos utilizados para avaliá-lo devem se relacionar e/ou evidenciar estes temas. Segundo entendemos, são eles os pontos-chave para que o programa de extensão não se configure como uma ação assistencialista e, prioritariamente, contribua para a formação dos futuros profissionais com uma visão crítica, reflexiva e comprometida socialmente. Em nosso caso, o programa estudado divulga como missão promover atividades pela inclusão das pessoas com deficiência, mas também a formação diferenciada dos estudantes que dele participam como colaboradores.

Vejamos, então, o detalhamento do instrumento principal utilizado para que os extensionistas avaliem o Centro e seus programas.

\section{O INSTRUMENTO PARA OS EXTENSIONISTAS E OS RESULTADOS OBTIDOS POR SUAAPLICAÇÃO E ANÁLISES DE SUAS AVALIAÇÕES EM 2008}

O roteiro para avaliação inicia com 3 questões fechadas, nas quais solicitase que os alunos escolham entre as alternativas muito bom, bom, regular e insuficiente, para avaliar (1) contribuições do programa para os extensionistas; (2) importância da supervisão, das atividades práticas e do grupo de estudo na aquisição de conhecimentos e (3) a equipe de apoio, a coordenação e os professores integradores.

Segue-se uma questão mista, em que os extensionistas avaliam se encontraram dificuldades na realização do projeto, assinalando sim ou não, podendo justificar sua resposta. $\mathrm{O}$ formulário termina com duas questões abertas, em que os participantes podem dar sugestões para a melhoria do programa e sintetizar, cursivamente, uma avaliação sobre o trabalho do Centro para a comunidade.

Como se pode verificar, não há no instrumento menção específica aos temas relacionados à articulação com ensino e pesquisa, interdisciplinaridade e inclusão social das pessoas com deficiência, o que consideramos um limite, porque seria muito importante garantir que os extensionistas se posicionassem em relação a eles. Apesar de os temas não estarem explicitamente indicados 
nas perguntas, os extensionistas poderiam falar a seu respeito nas três últimas questões, já que havia espaço para apresentar cursivamente suas avaliações.

Foram considerados 53 formulários respondidos pelos extensionistas ao final dos trabalhos desenvolvidos no ano de 2008. Quanto à articulação com os eixos de ensino e pesquisa, não encontramos nenhuma menção, nas respostas. Os extensionistas não tratam em suas avaliações o fato de que a extensão também deve gerar novos conhecimentos e, assim, enriquecer as atividades de ensino, nem que as pesquisas realizadas na universidade e as atividades de ensino alimentam os trabalhos desenvolvidos no Centro.

Os extensionistas mencionam a existência de contribuições para o desenvolvimento de seus Trabalhos de Conclusão de Curso (TCCs), o que está relacionado à articulação entre a extensão que realizam e as atividades de ensino, das disciplinas que cursam em suas graduações. Pode, também, estar articulado com o eixo da pesquisa, já que alguns TCCs na universidade têm esta natureza. Mas, de nosso ponto de vista, esta menção não chega a ser uma indicação do sentido mais profundo de indissociabilidade ensino-pesquisa-extensão.

O tema da interdisciplinaridade também não é mencionado nas respostas ao formulário. Já o tema inclusão é abordado pelos extensionistas, associado a: (i) dificuldades encontradas (falta de convívio anterior com pessoas com deficiência), (ii) aspectos apontados para a melhoria do programa (acessibilidade aos ambientes, incentivo e apoio financeiro para que os extensionistas possam participar de eventos científicos sobre inclusão) e, por fim, (iii) relacionado à avaliação do trabalho do Centro para a comunidade (entendem o trabalho como espaço que contribui para a integração da pessoa com deficiência na sociedade, valorizando seu potencial e habilidades). Além disso, em 20 formulários $(37,74 \%)$ aparecem termos correlatos à inclusão (integração e inserção); e 33 $(62,26 \%)$ não as citam.

A ausência de indicações pelos extensionistas sobre a questão da interdisciplinaridade nos parece um aspecto problemático, dada a importância que o programa propõe para seu desenvolvimento ${ }^{9}$. Por outra parte, a questão da inclusão é abordada por eles, o que merece ser destacado. Entretanto, o modo como isto ocorre pode ser considerado superficial ou pouco elucidativo e requereria um aprofundamento, a fim de tornar possível uma avaliação mais segura sobre o cumprimento dos objetivos do programa, principalmente quando se leva em conta a complexidade da questão da inclusão.

Conforme o que mencionamos a respeito de inclusão, incluir não é o mesmo que integrar, mas fazer com que a pessoa faça parte do processo, permitindo-

9 O termo "interdisciplinar" está incluso no nome real completo dado ao Centro. 
lhe participar da forma mais ampla possível, da vida em sociedade. Antes de tudo, são pessoas, portanto, com os mesmos direitos de ter um padrão de vida adequado às suas reais condições físicas e mentais, para que possam desenvolver suas capacidades com as adaptações e acessibilidade adequadas.

Chama-nos atenção o modo como os extensionistas abordam o que lhes parece contribuição do trabalho do Centro para a comunidade, o que não nos permite saber se, na concepção deles, predomina uma conotação assistencialista ou se estão se referindo a uma contribuição que prima pelo estímulo à autonomia das pessoas com deficiência, a uma dimensão formativa e/ou emancipatória destas pessoas.

Quanto às contribuições para a formação pessoal, as respostas giram em torno de reconhecerem uma melhora na maneira de se relacionar, indicam "maior preocupação com suas atitudes em relação a todas as pessoas nas mais diversas situações", e outras bastante similares.

Quanto aos aspectos negativos, as indicações referiram-se à estrutura e recursos materiais para o desenvolvimento do trabalho, como a necessidade de haver "espaços mais amplos", "equipamentos mais modernos, como novos computadores da sala de inclusão digital", maior oportunidade para "participação em eventos científicos específicos", "maior supervisão dos integradores, com mais estudo para entendimento técnico do que é realizado no Centro e a respeito das variadas deficiências".

Como sugestões de melhoria, destacam a necessidade de "maior divulgação deste trabalho no ambiente acadêmico", a "acessibilidade aos locais onde as atividades são realizadas" (relacionado à existência de rampas, elevadores, proximidade do ponto de ônibus), "necessidade de haver maior aproximação das atividades do próprio Centro", "necessidade de integração entre as atividades" e "mais oportunidades de socialização dos resultados".

Sem eliminar o valor das respostas, é necessário considerar que haveria muito a se perguntar aos extensionistas sobre os sentidos do que escrevem. Para nós, isto se aplica a maior parte das respostas, mas principalmente em relação àquelas que se referem à "maior aproximação das atividades do próprio Centro", "necessidade de integração entre as atividades", "maior supervisão dos integradores, com mais estudo". No processo de avaliação, estes esclarecimentos podem ter sido dados aos integradores e/ou à coordenadora; entretanto, o registro disto para compor o acervo de documentos do Centro seria importantíssimo, tanto para a avaliação do ano, como para preservar a história do Centro, da perspectiva de seus integrantes. 
Como hipótese para explicar a falta de perguntas e de respostas e/ou o registro de respostas ainda pouco precisas, quanto aos temas, é importante apontar para complexidade da construção de um instrumento de avaliação que dê conta de abordá-los (de modo que promovam a reflexão acerca do referencial do trabalho proposto pelo Centro, como interdisciplinaridade e inclusão). Estes dados nos mostram que a avaliação sobre o trabalho requereria um aprofundamento, a fim de tornar possível identificação mais segura sobre o cumprimento dos objetivos do programa.

Dentre os tópicos propostos por Worthen et al (2004), alcance e seleção das informações coletadas e completude e justiça, são, sem dúvida, os mais complexos, e aqueles em relação aos quais a avaliação realizada no Centro apresenta as maiores dificuldades. São, ao mesmo tempo, os mais fundamentais, tanto no sentido de terem que ser suficientes para dar conta de responder às "perguntas pertinentes sobre o programa e ser receptivos aos interesses dos clientes e de outros envolvidos" quanto se permitirem "examinar e documentar os pontos fortes e fracos do programa que está sendo avaliado, para que os pontos fortes sejam enfatizados e as áreas problemáticas sejam melhoradas". (p. 598)

Com relação ao alcance e seleção das informações coletadas, podemos dizer que as questões são abrangentes e procuram obter respostas que ajudem na avaliação do programa. Estas questões envolvem a avaliação realizada pelo e do extensionista, respondendo questões que dizem respeito ao Centro e a atuação destes estudantes no programa, os quais respondem anonimamente ao questionário sobre o Centro, e por meio do instrumento "avaliação individual do extensionista", respondem diretamente ao integrador responsável por cada projeto a respeito de sua participação e desenvolvimento na proposta, conforme descrevemos.

No que se refere à completude e justiça, entendemos que o processo é proposto com a intenção de contribuir para melhorar o programa, ou seja, o apontamento de seus pontos fortes e fracos, pelo qual espera-se que a Coordenadora do Centro e sua equipe façam revisão dos procedimentos administrativos e pedagógicos. Por ser um processo em construção - lembremo-nos que a avaliação formal e sistematizada começou a ser implantada em 2007 - portanto, não pode ser considerado completo. As informações coletadas são muito importantes, mas falta a interlocução mais aprofundada dos instrumentos com os temas que fazem parte do funcionamento do Centro, enquanto programa de extensão, tais como a interdisciplinaridade e as articulações com os eixos ensino e pesquisa, e com aqueles que são específicos à sua proposta, como a inclusão social das pessoas com deficiência. 
Pelas características do programa em análise, partimos do princípio de que é muito importante contemplar nos instrumentos e nas respostas dadas a eles pelos participantes da avaliação as questões relativas à articulação entre ensino, pesquisa e extensão, à interdisciplinaridade e à inclusão social das pessoas com deficiência. Entendemos que perguntas sobre estes temas serão, necessariamente, pertinentes, devem compor os interesses dos envolvidos, e precisam ser examinadas em seus pontos fortes e fracos.

Para finalizar, consideramos relevante apresentar algumas notas sobre a timidez de inclusão dos familiares/acompanhantes na avaliação e a não-participação das pessoas com deficiência. Pelo que verificamos, o primeiro segmento foi convidado a participar da avaliação somente no ano de 2007 ao responderem a um formulário cuja linguagem teve uma proposta mais acessível, mas que demonstra ainda não ter sido suficiente para atender à necessidade que um processo de avaliação tem de obter respostas que sejam mais elucidativas.

A Coordenadora explica que a ausência de participação destes dois segmentos deve-se ao fato de não ter sido, ainda, desenvolvida uma forma de avaliação e instrumentos que sejam adequados, isto é, numa linguagem acessível, uma vez que no referido grupo há baixa escolarização, ou dificuldade no domínio da leitura e da escrita. Para a Coordenadora, "a participação das pessoas com deficiência no processo de avaliação teria grande valor por participarem de uma atividade que possibilitaria serem ouvidos e assim, serem incluídos. A proposta de inclusão social seria bem mais completa no Centro".

Entretanto, é preciso destacar que a não-participação das pessoas com deficiência que freqüentam o Centro no processo de avaliação significa um estreitamento do alcance das informações importantes e das possibilidades de seleção das informações coletadas, ou melhor, uma problemática seleção prévia sobre quem é convidado a participar da coleta de informações.

Parece-nos correto o que a Coordenadora entrevistada afirma sobre a necessidade de se desenvolver procedimentos e instrumentos de avaliação que sejam adequados às características destas pessoas, isto é, numa linguagem acessível e/ou em outro tipo de linguagem que não a escrita, pelas limitações de escolarização dos deficientes e pelas próprias características das deficiências. Entretanto, como não há indicativos de que isto tenha ocorrido em qualquer período de seu funcionamento, é necessário refletir sobre este ponto, já que ouvir os usuários dos programas de extensão é imprescindível para garantirlhes o direito de participação mais completa, superar possíveis resquícios de assistencialismo, garantir a formação mais completa dos extensionistas pela oportunidade de ouvir a avaliação daqueles a quem suas ações se destinam e, 
por fim, para aquilatar com mais precisão as contribuições que esta extensão têm conseguido efetivar em relação às pessoas com deficiência.

\section{CONSIDERAÇÕES FINAIS}

Acreditamos que a universidade tem por finalidade acolher o estudante que, antes de tudo, é pessoa, e apontar-lhe caminhos para que possa fazer da sua formação pessoal, acadêmica e profissional, uma trajetória diferenciada, pela qual ele poderá destacar-se no mercado de trabalho, mas, sobretudo, contribuir para melhorias numa sociedade tão desigual como a brasileira. A universidade pode fazer mais do que cumprir o papel de ensinar, pesquisar e assistir à comunidade interna e externa: pode, também, preocupar-se com uma formação mais humanizada de seus estudantes e fazer deste indivíduo um cidadão mais comprometido e capaz de direcionar a sua atuação profissional e pessoal por uma sociedade menos injusta. Acreditamos que um dos meios pelo qual a universidade possa oferecer esta formação diferenciada seja pela extensão universitária.

A extensão universitária tem o compromisso, por um lado, com a universidade e com os alunos que nela se formam; e por outro, com os grupos sociais a quem se dirige e, portanto, com a sociedade em geral. Desse duplo compromisso derivam algumas exigências para a construção de uma extensão universitária com qualidade. Pelo primeiro, ela deve ter uma proposta de trabalho ampla, abrangente e que exige a interlocução com o ensino e a pesquisa. Deve, também, marcar-se pela interdisciplinaridade não só porque em seus programas, em geral, atuam estudantes e professores advindos de diferentes áreas do conhecimento, mas, principalmente porque esta é uma maneira rica de lidar com os conhecimentos já disponíveis e produzir novos conhecimentos sobre o mundo e sobre as pessoas. Pelo segundo, ela deve ser capaz de tornar disponíveis estes conhecimentos àquelas pessoas que estão fora do meio universitário e que não pertencem às parcelas da população mais privilegiadas. Isto deve ser feito com objetivo de dar oportunidade e instrumentos a elas para que contribuam para o enfrentamento das desigualdades sócio-econômicas do nosso país. Para tal, deve haver uma proposta de trabalho que se diferencie do assistencialismo e que não assuma para si aquilo que é responsabilidade dos governos e do Estado.

Extensão diz respeito ao estreitamento de laços com a sociedade, proporcionando condições para que o conhecimento converta-se em sabedoria, propondo-se que o ambiente universitário promova uma compreensão da existência humana, transcendendo a idéia de que a busca por conhecimento e 
aperfeiçoamento dos saberes tenha se resumido na mera busca por dinheiro e poder e/ou por mera minimização das mazelas sociais.

Neste contexto, os processos de avaliação reflexiva e crítica assumem um papel muito importante, porque podem/devem configurar-se como uma forma de saber com mais precisão o que se faz numa extensão, quem faz, como faz, para quem e por que faz. Além disso, a avaliação da extensão universitária não pode ser tratada de maneira isolada nas ações das IES, não só pela determinação das políticas atuais para o ensino superior, mas, também, porque quando se tem como meta a indissociabilidade entre ensino, pesquisa e extensão, a avaliação destes três eixos precisa ser feita de forma articulada.

Apesar de termos identificado uma carência de material sobre a avaliação da extensão, cumpre-nos dizer que a academia tem demonstrado interesse em debater as questões da avaliação institucional envolvendo os programas extensionistas, e ter encontrado espaço para esta discussão foi bastante satisfatório, principalmente nos eventos e os grupos de estudos específicos, tais como nos Congressos Brasileiros de Extensão Universitária, Fóruns e Seminários, atualmente os mais produtivos nesta esfera.

Destacamos a importância de que, ao refletir sobre o tema da avaliação institucional e da avaliação da extensão universitária, sejam consideradas as antecedidas por vários autores, diante das proporções com relação aos objetivos do processo avaliativo. Destacamos ainda a importância da participação dos sujeitos envolvidos na avaliação institucional, em todos os níveis hierárquicos da instituição, bem como os envolvidos nas ações desenvolvidas (comunidade interna e externa). Por fim, e provavelmente o mais importante, seja o valor da avaliação como instrumento de formação e de emancipação da instituição e dos indivíduos que dela fazem parte.

Podemos dizer que todo processo de avaliação, seus procedimentos, os instrumentos utilizados e os usos que se faz de seus resultados deve ser realizado/desenvolvido a partir dos objetivos daquilo que será avaliado; também é necessário conscientizar e preparar os participantes para este processo, a fim de que suas respostas sejam resultado de uma reflexão prévia, visando obter informações consistentes. Consideramos fundamental que os processos de avaliação da extensão levem em conta conceitos como a avaliação formativa e a emancipatória em contraposição ao conceito de avaliação autoritária. Somente assim, há possibilidade de que os participantes reflitam, criticamente, sobre o contexto sócio-político no qual se encontram, emancipem-se, de modo que possam conscientizar-se a respeito de possíveis necessidades de transformação, deste contexto. Uma avaliação deve conduzir a uma não- 
dependência dos mecanismos de controle e de alienação que sustentam uma sociedade capitalista.

Através das análises sobre o material empírico que produzimos, pudemos buscar responder às perguntas sobre os pontos fortes e as fragilidades de um processo de avaliação e fizemos algumas problematizações em relação ao nosso objeto de estudo, principalmente relativas a quem participa da avaliação e através de quais instrumentos o faz. Neste sentido, concordamos com Bartnik (2009) no que se refere à importância do cuidado na elaboração dos instrumentos e das estratégias de avaliação em programas de extensão.

O processo de avaliação deve considerar os diferentes segmentos de respondentes em suas especificidades, uma vez que há diferentes níveis de escolaridade, diferentes histórias de vida, os quais ocupam, então, posições diferentes em relação ao Centro, a partir dos quais podem avaliá-lo. Todas estas posições são importantes e cada instrumento de avaliação deve estar adequado às limitações e possibilidades daqueles que são convidados a dela participar. Podemos dizer que este cuidado é necessário nas avaliações de qualquer programa de extensão, já que, pela sua própria natureza incluirá sempre pessoas com diferenças importantes, a serem consideradas; no mínimo, as diferenças resultantes do fato de que qualquer extensão é um ponto de encontro entre acadêmicos e pessoas pertencentes aos níveis e grupos menos favorecidos da sociedade.

Com estes apontamentos finais, esperamos ter conseguido que os resultados deste trabalho contribuam para as reflexões sobre avaliação de programas de extensão universitária e sobre os modos como os estudantes universitários se apropriam das ações extensionistas, visando potencializar as reflexões sobre o próprio programa e sobre a contribuição destas ações que as universidades se propõem a desenvolver.

Tendo em perspectiva as questões até aqui postas, queremos encerrar com novas perguntas que nos foram instigando ao longo do trabalho: quais são as razões que levam o jovem, estudante universitário, que está em fase de lançar-se a novas descobertas e desafios muitas vezes impostos pela modernidade, pelo avanço tecnológico, pela liberdade de pensamento e de expressão, a se interessar por participar de um programa de extensão universitária que trabalha com pessoas com deficiência? Mesmo que este programa faça parte de um conjunto de opções que a universidade oferece como oportunidade de conseguir uma bolsa-estímulo ajudando-o com suas despesas da faculdade, há de se reconhecer que é um campo difícil de haver jovens atuando, dado o forte chamado a caminhos menos desafiadores para conseguir esta ajuda financeira. Desta maneira, uma possibilidade de continuidade da investigação estaria em 
buscar averiguar em quê está alicerçada esta atitude que aparenta desprendimento, não-preconceito, desejo de conhecer o diferente. Caso as razões e características destes estudantes sejam marcadas por genuíno interesse social, devem ser valorizados e estimulados, principalmente porque podem representar uma importante maneira de a universidade contribuir para, se não superar, ao menos atenuar as mazelas sociais do mundo e do nosso país.

\section{REFERÊNCIAS}

ARROYO, D. M. P. A meta-avaliação e a extensão universitária: um estudo de caso. 2010. Dissertação (Mestrado) - Pontifícia Universidade Católica de Campinas, Campinas, 2010.

BARTNIK, F. M. P. Ação extensionista em universidades católicas e comunitárias e sua avaliação. 2009. Dissertação (Mestrado) - Pontifícia Universidade Católica de Campinas, Campinas, 2009.

BRASIL. Ministério da Educação. Programa de Extensão Universitária - ROEXT.2003. Disponível em: <http://portal.mec.gov.br/index. php?option $=$ com_content $\&$ view $=$ article $\& i d=12241 \&$ Itemid $=487>$. Acesso em: ago 2009.

BRASIL. Lei 10.861, de 14 de abril de 2004. Institui o Sistema Nacional de Avaliação da Educação Superior - SINAES e dá outras providências. Brasília, DF, 14 abr. 2004.

CALDERÓN, A. I. et al. Educação superior: construindo a extensão universitária nas IES particulares. São Paulo: Xamã, 2007.

DIAS SOBRINHO, J.; RISTOFF, D.I. (Orgs.). Avaliação democrática: para uma universidade cidadã. Florianópolis: Insular, 2002.

ELPO, M. E. H. C. Avaliação da extensão universitária na proposta do SINAES. In: CONGRESSO BRASILEIRO DE EXTENSÃO UNIVERSITÁRIA, 2., 2004, Belo Horizonte. Anais... Belo Horizonte: [s.n.], 2004. 
NOGUEIRA, M. das D. P. Políticas de extensão universitária brasileira. Belo Horizonte: UFMG, 2005.

SEVERINO, A. J. Metodologia do trabalho científico. 23. ed. São Paulo: Cortez, 2007.

SILVA, P. B. A dimensão da extensão nas relações com o ensino e a pesquisa. In: ARAGÃO, R.; SANTOS NETO, E. dos; SILVA, P. B. da. Tratando da indissociabilidade ensino, pesquisa, extensão. São Bernardo do Campo: UMESP, 2000.

SOUSA, A. L. L. A história da extensão universitária. Campinas: Alínea, 2000 .

THIOLLENT, M. Construção do conhecimento e metodologia da extensão. In: CONGRESSO BRASILEIRO DE EXTENSÃO UNIVERSITÁRIA, 1., 2002. Disponível em: $<$ http://www.prac.ufpb.br/Icbeu_anais/apresentacao/ apresentacao $>$. Acesso em: fev.2010.

VILLAS BOAS, B. M. de F. (org). Avaliação: políticas e práticas. Campinas: Papirus, 2006.

WORTHEN, R. B.; SANDERS, J. R.; FITZPATRICK, J. L. Avaliação de programas: concepções e práticas. Trad. Dinah de Abreu Azevedo. São Paulo: Gente, 2004 
Este artigo sofreu alterações por solicitação do editor em Nov/2010 conforme ERRATA

publicada no Volume 15 Número 3 do periódico. (http://www.scielo.br/pdf/aval/v15n3/12.pdf) 